\title{
Erratum: Analysis of possible systematic errors in the Oslo method [Phys. Rev. C 83, 034315 (2011)]
}

A. C. Larsen, M. Guttormsen, M. Krtička, E. Běták, A. Bürger, A. Görgen, H. T. Nyhus, J. Rekstad, A. Schiller, S. Siem, H. K. Toft, G. M. Tveten, A. V. Voinov, and K. Wikan

(Received 28 February 2018; published 10 April 2018)

DOI: 10.1103/PhysRevC.97.049901

A misprint in Eq. (38) has been discovered; the inverse of the numerator of the last term on the right-hand side had been given inadvertently. The expression was coded correctly, and so none of the results will change; it was only a typographical error in the article itself.

Equation (38) was given as

$$
\rho\left(S_{n}\right)=\frac{\sigma^{2}}{D_{0}} \frac{(1 \pm \alpha) / 2}{\left(I_{t}+1\right) \exp \left[-\left(I_{t}+1\right)^{2} / 2 \sigma^{2}\right]+I_{t} \exp \left[-I_{t}^{2} / 2 \sigma^{2} s\right]},
$$

and this should however be corrected to

$$
\rho\left(S_{n}\right)=\frac{\sigma^{2}}{D_{0}} \frac{2}{1 \pm \alpha} \frac{1}{\left(I_{t}+1\right) \exp \left[-\left(I_{t}+1\right)^{2} / 2 \sigma^{2}\right]+I_{t} \exp \left[-I_{t}^{2} / 2 \sigma^{2}\right]} .
$$

None of the results presented in the article are affected by the misprint.

The authors thank L. Crespo Campo for discovering the misprint. 